NASA/TM-1998-206628

\title{
A Modular PMAD System for Small Spacecraft
}

Robert M. Button

Lewis Research Center, Cleveland, Ohio

Prepared for the

Space Technology and Applications International Forum cosponsored by DSWA, NASA, DOE, and USAF

Albuquerque, New Mexico, January 26-30, 1998

National Aeronautics and

Space Administration

Lewis Research Center 
Available from

NASA Center for Aerospace Information

800 Elkridge Landing Road

Linthicum Heights, MD 21090-2934

Price Code: A03
National Technical Information Service 5287 Port Royal Road Springfield, VA 22100 Price Code: A03 


\title{
A Modular PMAD System for Small Spacecraft
}

\author{
Robert M. Button \\ National Aeronautics and Space Administration \\ Lewis Research Center \\ 21000 Brookpark Rd. \\ Cleveland, Ohio 44135
}

(216) $433-8010$

\begin{abstract}
Current trends in satellite design are focused on developing small, reliable, and inexpensive spacecraft. To that end, a modular power management and distribution system (PMAD) is proposed which will help transition the aerospace industry towards an assembly line approach to building spacecraft. The modular system is based on an innovative DC voltage boost converter called the Series Connected Boost Regulator (SCBR). The SCBR uses existing DC-DC converters and adds a unique series connection. This simple modification provides the SCBR topology with many advantages over existing boost converters. Efficiencies of 94$98 \%$, power densities above $1,000 \mathrm{~W}_{\mathrm{e}} / \mathrm{kg}$, and inherent fault tolerance are just a few of the characteristics presented. Limitations of the SCBR technology are presented, and it is shown that the SCBR makes an ideal photovoltaic array regulator. A modular design based on the series connected boost unit is outlined and functional descriptions of the components are given.
\end{abstract}

\section{Introduction}

In the past few years the spacecraft industry has shifted their sights away from large, expensive, decade-long projects towards small and inexpensive satellites. Low cost spacecraft that can be developed in 2-3 years are being considered the wave of the future in space science and new global communication systems. These new systems will provide global communications through constellations of 66 to 840 small, inexpensive satellites. It is clear that the satellite industry must transition from building custom satellites towards an "assembly line" approach.

A small, lightweight, efficient PMAD system is a key component. By minimizing size, the spacecraft can support more payload and/or require smaller launch vehicles. By maximizing efficiency, the spacecraft will have better power utilization, further reducing mass and cost. A new DC-DC power processing technology is showing great promise in bringing small, efficient, and inexpensive source regulation to a modular power system architecture.

\section{Series Connected Boost Regulator}

The Series Connected Boost Regulator (SCBR) is not a new DC-DC converter topology. Instead, it is a unique interconnect topology which makes novel use of an isolating DC-DC converter. The Series Connected Boost Regulator is based on the principle of biasing an isolated voltage source on top of another source. Figure 1 shows the very simple series connection of two isolated DC sources. The two voltage sources in Figure 1 add together to provide $28 \mathrm{Vdc}$ to a $2.8 \Omega$ load. The load current, $\mathrm{I}=10 \mathrm{~A}$, is the same in each source since they are connected in series. The DC-DC converter input current can be calculated as $4.7 \mathrm{~A}$ using the output power and efficiency of the DC-DC converter.

$$
\begin{gathered}
P_{i n}=\frac{P_{d c}}{e}=\frac{8 \mathrm{~V} \cdot 10 \mathrm{~A}}{0.85}=94 \mathrm{~W} \\
I_{d c}=\frac{P_{\text {in }}}{V_{\text {in }}}=\frac{94 \mathrm{~W}}{20 \mathrm{~V}}=4.7 \mathrm{~A}
\end{gathered}
$$

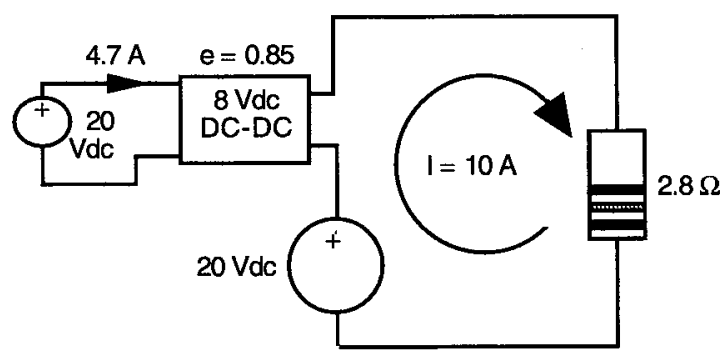

FIGURE 1. Isolated DC-DC Converters in Series.

Since the DC-DC converter is isolated, we can use a single $20 \mathrm{Vdc}$ power supply to bias the voltage 
across the load and power the DC-DC converter. The circuit has been redrawn in Figures $2 a$ and $2 b$ to show the single power supply. Note that all circuit parameters remain the same.

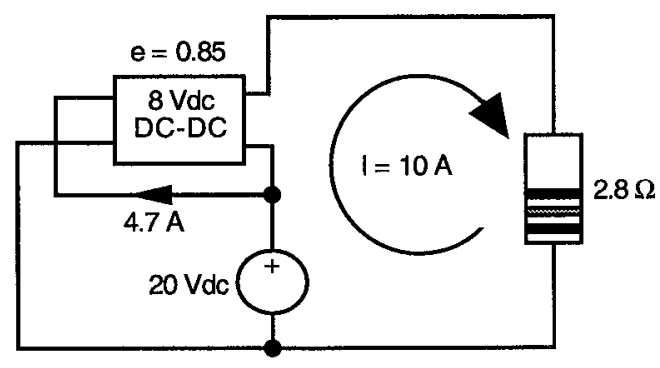

FIGURE 2a. Using a Single $20 \mathrm{Vdc}$ Supply.

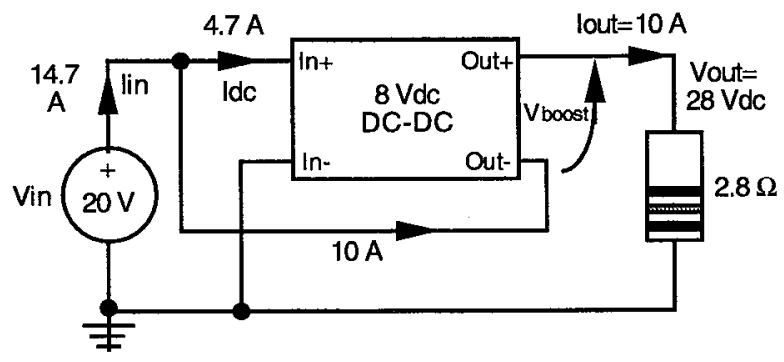

FIGURE 2b. Series Connected Boost Regulator.

The benefits of the SCBR are clear once we analyze the circuit and examine the steady-state characteristics of the converter.

\section{High Efficiency}

The SCBR benefits from high end-to-end efficiency because it only processes a portion of the power delivered. Efficiencies of $94 \%$ to $98 \%$ have been measured in the lab on a variety of SCBRs. These high efficiencies are possible with off-the-shelf DCDC converters $(75-85 \%$ efficiency) allowing designers to easily develop high efficiency components without the high cost of a custom design. In the circuit shown in Figure $2 b$, a typical DC-DC converter with an efficiency of $85 \%$ is being used in the SCBR configuration. The efficiency of the SCBR can be calculated from the circuit parameters as:

$$
e_{s c b u}=\frac{P_{\text {out }}}{P_{\text {in }}}=\frac{28 \mathrm{~V} \cdot 10 \mathrm{~A}}{20 \mathrm{~V} \cdot 14.7 \mathrm{~A}}=\frac{280 \mathrm{~W}}{294 \mathrm{~W}}=95.2 \%
$$

A general-purpose equation for the efficiency of a series connected boost unit can be derived from the
SCBR circuit shown in Figure 2b. The simplified equation for the efficiency of the SCBR is (Button 1996):

$$
e_{s c b u}=\frac{V_{i n}+V_{b o o s t}}{V_{i n}+\frac{V_{b o o s t}}{e_{d c}}}
$$

The equation of (1) has a few limitations. First, the boost voltage cannot equal zero and must be greater than the rectifier diode "on" voltage in the output of the DC-DC converter. This is to account for the diode conduction losses when the SCBR is "off". Also, it must be recognized that the efficiency of the DC-DC converter, $\mathrm{e}_{\mathrm{dc}}$, is a complex function of output power, input voltage, and boost voltage. Typical DC-DC converters reach their nominal efficiency above $40 \%$ rated power. However, the SCBR exhibits high efficiency over the entire power range since the main factor in determining SCBR efficiency is the difference between $V_{i n}$ and $V_{\text {boost }}$.

\section{High Power Density}

The amount of power controlled by the SCBR can be 2-5 times the power rating of the DC-DC converter, greatly increasing its power density. This is because only a portion of the power is being processed by the DC-DC converter. The power processing gained depends on the output voltage desired $\left(\mathrm{V}_{\text {out }}\right)$ and the maximum output current of the DC-DC converter $\left(\mathrm{I}_{\text {out }}\right)$. Since the output current is a function of the maximum boost voltage and the DC$\mathrm{DC}$ converter power rating, the power rating of the SCBR can be expressed as a function of $V_{\text {out }}, V_{\text {boost }}$, and $P_{d c}$.

$$
\begin{gathered}
P_{s c b u}=I_{\text {out }} \bullet V_{\text {out }} I_{\text {out }}=\frac{P_{d c}}{V_{b o o s t}(\max )} \\
P_{\text {scbu }}=\frac{V_{\text {out }}}{V_{\text {boost }}(\max )} \bullet P_{d c}
\end{gathered}
$$

As shown in (3), the power rating of the SCBR can be maximized by minimizing the DC-DC converter boost voltage. Using Figure $2 b$ as an example, an 80 Watt, $8 \mathrm{Vdc}$ converter controlling a $28 \mathrm{Vdc}$ bus results in a power processing capability of 280 Watts -- a $250 \%$ increase in power density. Larger gains are possible when considering higher bus voltages. In a recent program, a nominal $120 \mathrm{Vdc}$ bus was regulated using a $1 \mathrm{~kW}_{\mathrm{e}}, 28 \mathrm{Vdc}$ converter. The resulting SCBR was able to process $4.25 \mathrm{~kW}_{\mathrm{e}}$, an increase of $325 \%$ (Button and Baez 1995). 


\section{Inherent Fault Tolerance}

In many spacecraft power systems, a failure of the power processing hardware can result in complete loss of power and loss of mission. Since this hardware is so critical, fault tolerance requirements usually dictate an $\mathrm{N}+1$ redundancy scheme requiring extra hardware being flown as on-line backups in case of failure. Should one module fail, the extra module automatically comes on-line resulting in little or no loss of power. However, this scheme says nothing about catastrophic failures involving 2 or more units.

The SCBR topology can augment $\mathrm{N}+1$ redundancy due to the inherent fault tolerance built into the design. In DC-DC converters, the input switching bridge is the most likely component to fail. In the SCBR configuration, a failure of the DC-DC converter input bridge will not prevent power delivery to the main bus due to the series connection. Raw input power will be available at the SCBR output allowing emergency operation of the satellite. This feature increases the spacecraft's fault tolerance abilities.

\section{Positive Ground Configuration}

The SCBR technology also allows the spacecraft designer the option of implementing a positive ground power system. A positive ground power system can be very effective in reducing the buildup of damaging plasma on high voltage solar arrays (Hickman 1995). The positive ground topology is shown in Figure 3.

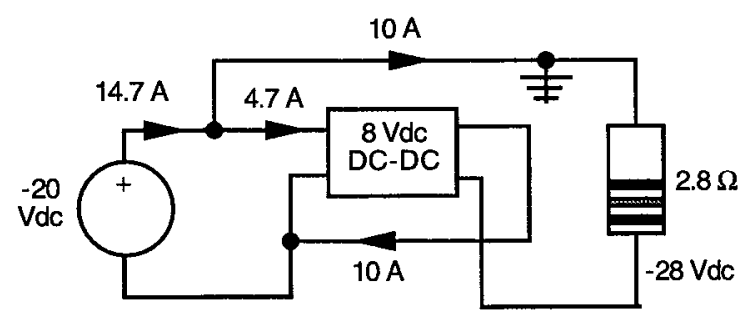

FIGURE 3. SCBR Positive Ground Configuration.

Instead of connecting Out- to Int as is shown in Figure $2 b$, the positive ground topology connects Out+ to In-. This allows the power supply's high side to be common with the load's high side allowing the positive ground connection. The positive ground topology has been demonstrated in a test bed development program at NASA Lewis.
A $1 \mathrm{~kW}_{\mathrm{e}}$ DC-DC converter was modified for use in a $4.5 \mathrm{~kW}_{\mathrm{e}}$ positive ground power system for a Solar Electric Propulsion spacecraft (Button and $\mathrm{Baez}$ 1995).

\section{Commercial DC-DC Converters}

The SCBR technology uses isolated DC-DC stepdown converters to control the amount of boost added to an input voltage. These DC-DC converters are readily available from several manufacturers in various quality levels (industrial, military, and flight qualified). Although they are not optimized for efficiency, it was shown earlier that the efficiency of the DC-DC converter is only a small factor in the SCBR efficiency. Using the SCBR technology, a very high efficiency converter can be built using inexpensive commercial DC-DC converters.

\section{SCBR Limitations}

The SCBR benefits of efficiency and power density come at a price. There are three limitations that a power system must meet to take full advantage of the SCBR topology:

1) The SCBR requires that the output voltage be greater than or equal to the input voltage at all times,

2) Galvanic isolation must not be required between input and output circuits, and

3) The input voltage source has a limited voltage range requiring only a small percentage $(<50 \%)$ of voltage boost.

Many spacecraft power systems already meet these criteria. Photovoltaic power systems are an excellent example. A photovoltaic array can be easily sized during construction such that its output voltage is below the bus voltage at all times. Galvanic isolation between the array and power bus is not a requirement in most systems. In addition, the solar array I-V curve is such that all power points can be reached over a small voltage range (between $\mathrm{V}_{\mathrm{mp}}$ and $\mathrm{V}_{\mathrm{oc}}$ ), requiring only a small boost ratio (Figure 4). 


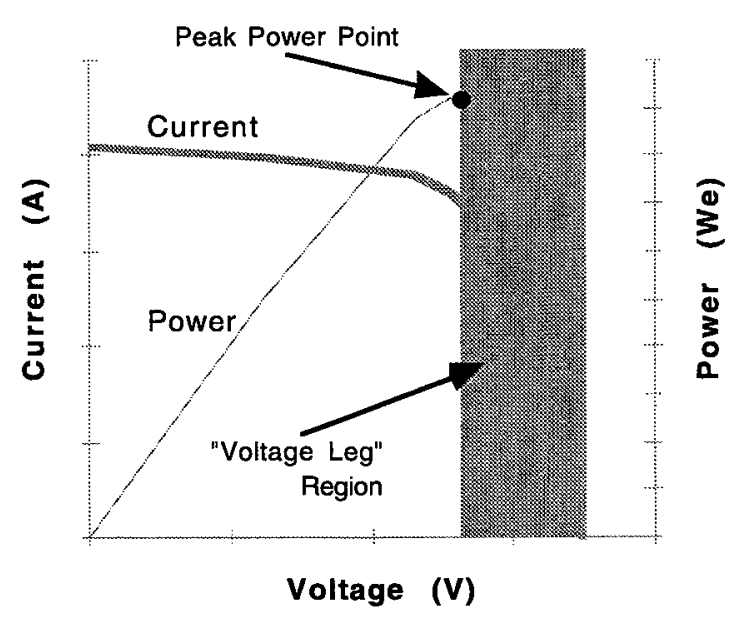

FIGURE 4. Solar Array I-V and P-V curves

Other systems that can benefit from the SCBR technology all have the same common features the need for a regulated DC voltage from an unregulated DC source that has a limited voltage range. Some of these other applications include: 1) High current DC power systems requiring tight voltage regulation at the load, 2) Thermionic diode power systems which have distinct I-V curves with limited voltage ranges (Kimnach 1996), and 3) Battery voltage regulators which provide a fixed output voltage as the battery voltage droops during discharge.

Even with these limitations, it is obvious that the SCBR technology is enabling a new class of small, low cost, high efficiency power electronics to meet the special needs of small spacecrafts in increasing payload capacity. To add even more value, a modular design based on the SCBR technology is presented.

\section{A Modular PMAD System}

The power management and distribution (PMAD) system on a typical satellite is expected to act as the "electric utility" providing regulated power to the spacecraft systems and scientific payloads. Although there are slight variations due to different payload needs and orbit geometries, most LEO satellites have very similar electric power system requirements. These requirements can be generalized as: managing battery charge rates by regulating the solar array output, protecting the satellite from load and system faults, and reporting status information to the spacecraft computer. These similarities in the power system requirements can lead directly to similar power systems. However, most satellite power systems are still designed from scratch using many one-of-a-kind components. These high cost components must be replaced by flexible, modular components if the promise of small, low cost spacecrafts are to be realized.

The benefits of a truly modular PMAD system are many. Since modular components can be used in a variety of missions, the large quantity of modules manufactured decreases the price per module. The ability to add modules makes designing $\mathrm{N}+1$ redundancy very easy. Finally, the 12-16 month design and development phase associated with custom components is eliminated. The system design is simplified to selecting and integrating preengineered modules to meet the needs of the spacecraft; further reducing cost and compressing schedule.

A modular PMAD component is one which can meet a wide variety of mission requirements, i.e. power source inputs, bus voltage and power levels, telemetry, and load switching features. Modularity can be designed into PMAD components using a combination of techniques such as: wide operating range components, added "scars and hooks", built-in paralleling capabilities, and device-swapping designs. For example, an SCBR is needed to regulate a nominal $28 \mathrm{Vdc}$ solar array at currents up to $20 \mathrm{~A}$. Instead of sizing the components to handle the $28 \mathrm{Vdc}$ and $20 \mathrm{~A}$, use passive components and wires that can support $72 \mathrm{Vdc}$ at up to $50 \mathrm{~A}$. The small penalty paid in size and weight is well worth the flexibility of supporting higher voltage, higher power missions with the same component design.

A block diagram of a proposed modular PMAD system based on the SCBR technology is shown in Figure 5. This system is a dual-wing photovoltaic system with a battery-centric bus architecture. Besides the power generation and storage systems, the PMAD system consists of three major components. Each component employs a number of modular techniques to meet the wide variety PMAD system requirements. A discussion of these component design features follows.

\section{The Power Input Unit}

The Power Input Unit is used to bus all solar array sources necessary to power the PMAD channel(s). This unit will also be designed to support a multichannel PMAD architecture. Included in this unit is the solar array telemetry (voltage and current sensors) which will be capable of supporting voltages up to $72 \mathrm{Vdc}$ and currents up to $50 \mathrm{~A}$. This means that passive components and telemetry will be able to handle the higher voltages and all cables 


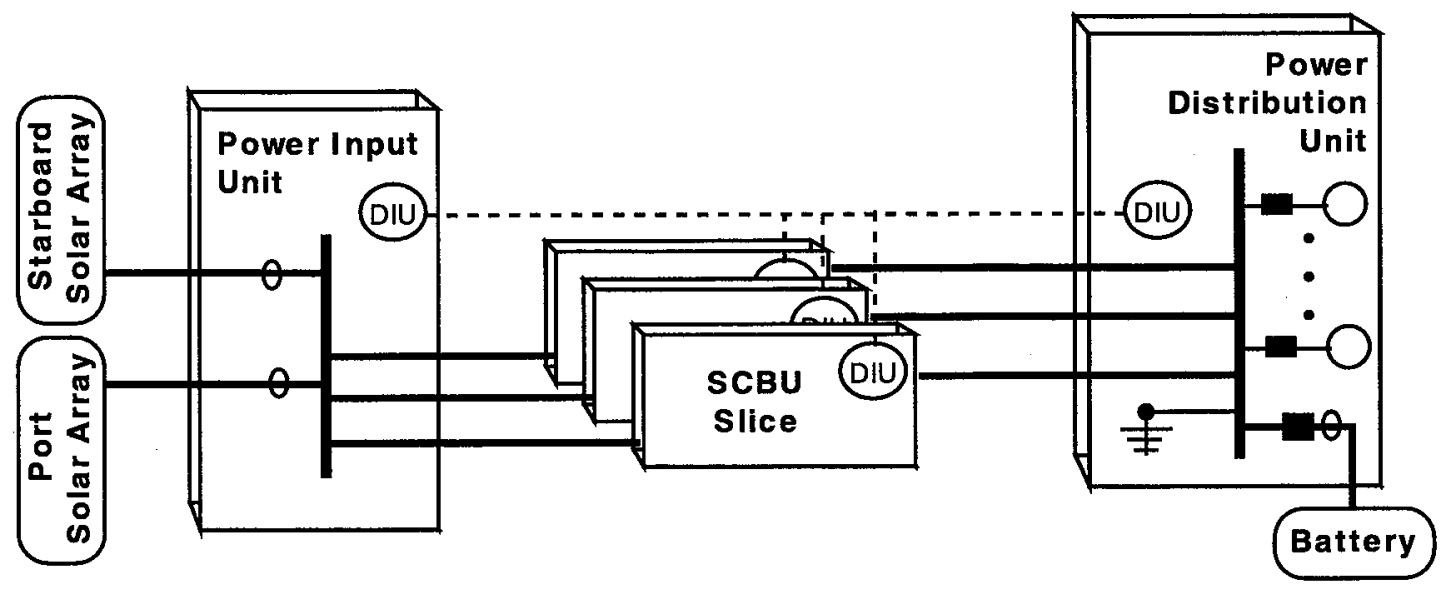

FIGURE 5. A modular PMAD System Using SCBR Slices

and connectors will be sized for $50 \mathrm{~A}$. Also, peak power tracker circuitry will be included to detect peak power point crossings. This circuitry will interface with the power processing hardware (SCBRs) through discrete analog signals and/or an optional Data Interface Unit (DIU).

\section{The SCBR Slice(s)}

The SCBR slices are pre-engineered power processing units used to provide solar array regulation. These modular components contain all the circuitry necessary to operate independently and/or in parallel with other units. The SCBR slice includes: EMI filters, DC-DC converters, fault protection fuses, voltage and current sensors, voltage and current regulators, On/Off control, paralleling circuitry, and telemetry. Again, all passive components (capacitors, resistors, etc.) and telemetry circuits will be sized for voltages up to 72 Vdc and currents up to $50 \mathrm{~A}$.

The SCBR slice design will incorporate a common controller circuit card which can be used in any SCBR slice. This analog circuit card will provide: telemetry, voltage and current controllers, paralleling circuitry, peak power tracking, and On/Off control. Telemetry and setpoint interfacing will be implemented through discrete analog signals. A Data Interface Unit (DIU) option can be added to provide telemetry and health monitoring to the spacecraft computer through a serial link.

The SCBR will support a wide variety of power and voltage levels by making the DC-DC converter an interchangeable component. Single slice power levels of $250 \mathrm{~W}_{\mathrm{e}}$ and $500 \mathrm{~W}_{\mathrm{e}}$ have been implemented using commercial hardware. The selected DC-DC converter will interface with the input and output power buses and common controller card through its own power circuit card. This card will mount on top of the DC-DC converter and contain the following elements: EMI filters, input and output power buses, the series connection, current sensors, and input protection fuses. These components will also be sized for a wide range of voltage and current levels to support many DC-DC converters.

Finally, a paralleling function will be built into each SCBR slice. There will be two paralleling methods available. An active paralleling loop will be used to balance SCBR power levels when regulating output voltage. This circuitry incorporates a shared paralleling bus which will actively bias the SCBR voltage sense until a balanced current is achieved. This method can be used with several slices and can incorporated \% current sharing. Another paralleling method can be used when the SCBR slice is used to regulate output current. In this case, power sharing is achieved by setting the output current setpoints of all SCBRs to desired power sharing levels, either through discrete analog circuits or through the optional DIU.

\section{The Power Distribution Unit}

The Power Distribution Unit (PDU) serves several purposes and contains: the main distribution bus, the battery charge management circuitry, the spacecraft single point ground, and the PMAD housekeeping power supplies. The PDU must provide power to all spacecraft loads through a variety of fault protection components based on the needs of the spacecraft. These components can incorporate fuses, relays, and/or active switching devices. Use of modular fault protection switches and a family of fuse sizes will simplify the design of the power distribution unit. 
The PDU connects the battery to the main bus through fault protection fuses. These fuses are only necessary in a multi-channel power system since in a single channel system there is no fault condition which could be recovered by blowing the battery fuse. Battery health monitoring is provided through the PDU and includes: battery current, battery voltage, cell voltage, and cell temperature data. Specialized microprocessors will be incorporated into the PDU to determine the battery state of charge, thereby off-loading this function from the main spacecraft computer. As before, the sensors and passive components will be sized for a wide range of bus voltage levels and the telemetry and control functions will be discrete analog signals with a DIU option available.

Finally, all PMAD hardware requires electrical power to deliver electrical power -- a seemingly "catch 22" scenario. This "housekeeping" power supply function will also reside in the PDU and consists of small, isolated DC-DC converters. These wide voltage range converters $(18-72 \mathrm{Vdc})$ will convert the bus voltage into $+5 \mathrm{Vdc}$ and $\pm 15 \mathrm{Vdc}$. By positioning the power supplies in the PDU, the PMAD system can be boot-strapped from either the charged battery or from raw solar array power. Since the housekeeping power supplies perform a critical function, single fault tolerance will be incorporated by including on-line backup converters. This centralized power distribution will eliminate the need for dual (or even quad) power supplies in every modular component (SCBR slices and PIU).

\section{Conclusions}

It is clear that the spacecraft industry must incorporate modular systems to be competitive in the 21st century. A modular PMAD system based on the SCBR technology has shown promise in meeting the needs of a wide variety of missions. The SCBR has many advantages over other regulators. It is very efficient, has very high power density, and benefits from an inherent fault tolerance. These qualities all add up to smaller, lightweight spacecraft which can be developed quickly and economically.

\section{References}

Beach, R.F. and A.S. Brush (1993) "Series Connected Converter for Control of Multi-Bus Spacecraft Power Utility," NASA Disclosure of Invention \#LEW15918-1C, NASA Lewis Research Center, Cleveland, $\mathrm{OH}$.

Button, R.M. (1996) "An Advanced Photovoltaic Regulator Module", in Proceedings, 31st Intersociety Energy Conversion Engineering Conference, Washington, D.C., 1:519-525

Button, R.M. and A.N. Baez (1995) "A Modular Electric Power System Test Bed for Small Spacecraft," NASA Technical Memorandum \#106812, NASA Lewis Research Center, Cleveland, $\mathrm{OH}$.

Hickman, J.M. (1994) "Solar Electric Propulsion for Magnetospheric Mapping," in Proceedings, 30th AIAA/ASME/ SAE/ASEE Joint Propulsion Conference.

Kimnach, G.L. (1996) "Design of a Power Management and Distribution System for a Thermionic Diode Powered Spacecraft," in Proceedings, 31st Intersociety Energy Conversion Engineering Conference, Washington, D.C., 1:529531 
Public reporting burden for this collection of information is estimated to average 1 hour per response, including the time for reviewing instructions, searching existing data sources, gathering and maintaining the data needed, and completing and reviewing the collection of information. Send comments regarding this burden estimate or any other aspect of this collection of information, including suggestions for reducing this burden, to Washington Headquarters Services, Directorate for Information Operations and Reports, 1215 Jefferson Davis Highway, Suite 1204, Arlington, VA 22202-4302, and to the Office of Management and Budget, Paperwork Reduction Project (0704-0188), Washington, DC 20503.

\begin{tabular}{|l|l|l}
\hline 1. AGENCY USE ONLY (Leave blank) & $\begin{array}{c}\text { 2. REPORT DATE } \\
\text { January } 1998\end{array}$ & $\begin{array}{r}\text { 3. REPORT TYPE AND DATES COVERED } \\
\text { Technical Memorandum }\end{array}$
\end{tabular}

4. TITLE AND SUBTITLE

A Modular PMAD System for Small Spacecraft

6. AUTHOR(S)

Robert M. Button

7. PERFORMING ORGANIZATION NAME(S) AND ADDRESS(ES)

National Aeronautics and Space Administration

Lewis Research Center

Cleveland, Ohio 44135-3191

9. SPONSORING/MONITORING AGENCY NAME(S) AND ADDRESS(ES)

National Aeronautics and Space Administration

Washington, DC 20546-0001
WU-632-1A-1C

8. PERFORMING ORGANIZATION

REPORT NUMBER

E-11072

\section{SUPPLEMENTARY NOTES}

Prepared for the Space Technology and Applications International Forum cosponsored by DSWA, NASA, DOE, and USAF, Albuquerque, New Mexico, January 26-30, 1998. Responsible person, Robert M. Button, organization code 5450, (216) 433-8010.

\section{2a. DISTRIBUTION/AVAILABILITY STATEMENT}

Unclassified - Unlimited

Subject Category: 20

Distribution: Nonstandard

This publication is available from the NASA Center for AeroSpace Information, (301) 621-0390.

13. ABSTRACT (Maximum 200 words)

Current trends in satellite design are focused on developing small, reliable, and inexpensive spacecraft. To that end, a modular power management and distribution system (PMAD) is proposed which will help transition the aerospace industry towards an assembly line approach to building spacecraft. The modular system is based on an innovative DC voltage boost converter called the Series Connected Boost Regulator (SCBR). The SCBR uses existing DC-DC converters and adds a unique series connection. This simple modification provides the SCBR topology with many advantages over existing boost converters. Efficiencies of $94-98 \%$, power densities above $1,000 \mathrm{We} / \mathrm{kg}$, and inherent fault tolerance are just a few of the characteristics presented. Limitations of the SCBR technology are presented, and it is shown that the SCBR makes an ideal photovoltaic array regulator. A modular design based on the series connected boost unit is outlined and functional descriptions of the components are given.

\section{SUBJECT TERMS}

Power converters; Spacecraft electronic equipment; Voltage converters--DC to DC 15. NUMBER OF PAGES 12

16. PRICE CODE

$\mathrm{A03}$

\begin{tabular}{|c|c|c|}
\hline $\begin{array}{c}\text { 17. SECURITY CLASSIFICATION } \\
\text { OF REPORT } \\
\text { Unclassified }\end{array}$ & $\begin{array}{c}\text { 18. SECURITY CLASSIFICATION } \\
\text { OF THIS PAGE } \\
\text { Unclassified }\end{array}$ & $\begin{array}{c}\text { 19. SECURITY CLASSIFICATION } \\
\text { OF ABSTRACT } \\
\text { Unclassified }\end{array}$ \\
\hline
\end{tabular}

NSN 7540-01-280-5500 
